\title{
Exploring cultural differences in wildlife value orientations using student samples in seven nations
}

\author{
Maarten H Jacobs ${ }^{1}$ (D) . Sara Dubois ${ }^{2} \cdot$ Tetsuro Hosaka $^{3} \cdot$ Vukan Ladanović ${ }^{4}$. \\ Huda Farhana Mohamad Muslim ${ }^{5} \cdot$ Kelly K. Miller $^{6}$. Shinya Numata ${ }^{7}$. \\ E. Ranaweerage ${ }^{8} \cdot$ Tanja M. Straka $^{9} \cdot$ Michael A. Weston $^{9}$. \\ Zulkhairi Azizi Zainal Abidin ${ }^{10}$
}

Received: 3 September 2020 / Revised: 29 December 2021 / Accepted: 2 January 2022 /

Published online: 12 January 2022

(c) The Author(s) 2022

\begin{abstract}
Understanding differences in the way people think about wildlife across countries is important as many conservation challenges transcend jurisdictions. We explored differences in wildlife value orientations in seven countries: Australia, Canada, Germany, Japan, Malaysia, the Netherlands and Serbia. Standard scales assessed domination (prioritizing human well-being) and mutualism (striving for egalitarian relationships with wildlife). We used student samples (total $\mathrm{n}=2176$ ) for cross-cultural comparisons. Reliabilities of the wildlife value orientations scales were adequate in all countries. Relationships between demographics and wildlife value orientations were different across countries. Men were generally more oriented towards domination and less towards mutualism than women, except in Serbia, where it was the other way around. Estimated at the level of the individual (using ANOVA), wildlife value orientations varied across countries, with nationality explaining a larger portion of the variation in mutualism $(21 \%)$ than domination $(6 \%)$. Estimated at the level of countries (using multilevel modelling), effect sizes were comparable. Thought about wildlife has previously only been examined within single countries. This paper makes a new contribution to the conservation literature suggesting that wildlife value orientations vary by country, and are associated with demographic factors. For conservation practices, understanding national differences in the way people think about wildlife is crucial to understanding sources of conflict among practitioners. Such knowledge is also important to gain public support for conservation.
\end{abstract}

Keywords Cross-national research $\cdot$ Demographics $\cdot$ Domination $\cdot$ Human-wildlife relationships $\cdot$ Mutualism

Communicated by Anurag chaurasia.

This article belongs to the Topical Collection: Biodiversity appreciation and engagement.

Extended author information available on the last page of the article 


\section{Introduction}

Wildlife and wildlife conservation challenges transcend nations (Manfredo 2008; Ntuli et al. 2019; Teel et al. 2007; Zainal Abidin and Jacobs 2016). Wolves Canis lupus, for example, have migrated from Poland to Germany in the recent past, and are now returning to the Netherlands (Dressel et al. 2015; Jacobs et al. 2014a). Non-native species, colonizing new geographical domains, present challenges for wildlife managers. Jurisdictions vary per country and wildlife policies can have different objectives and funding priorities (Vitule et al. 2019). Many people living in countries without tigers Panthera tigris, for example, are so passionate about tigers that they make financial contributions for their conservation (Macdonald et al. 2015; Zainal Abidin 2019). The people who actually live in the same areas as tigers, however, sometimes come into conflict with them, and might therefore have different opinions (Zainal Abidin 2019). The global popularity of tigers has led to international co-operation on tiger conservation (Bhandari et al. 2019). Consequently, conservation funds are often transferred between countries (Anyango-van Zwieten et al. 2019). Awareness of culturally shaped differences in beliefs and values in cross-national teams fosters effectiveness in addressing conservation challenges (Bruyere 2015) by creating a widely supported conservation strategy (Bhatia et al. 2020). Also, public support is ultimately crucial to conservation success (Dietsch et al. 2016). For these reasons, research that addresses differences in the way people think about wildlife across countries can contribute to conservation scholarship and practice. This paper makes a novel contribution to the literature by examining differences in wildlife value orientations in student samples across seven countries.

\section{Theoretical framework}

Wildlife value orientations are patterns of basic beliefs that give meaning and direction to fundamental values in the context of human-wildlife relationships (Fulton et al. 1996; Jacobs et al. 2019). Theory proposes that wildlife value orientations reflect general ideologies (Jacobs et al. 2019) and exist at the macro-level (societies) as cultural ideologies. These ideologies are conveyed, reinforced and transformed through social interaction, in the form of, for instance, expressions, institutions and governance systems (Lehman et al. 2004). During their formative years, individuals are socialized into members of a culture on the basis of perpetual communicative interactions with social agents (e.g., peers, family, teachers, media). Individuals tend to adopt pre-existing cultural ideologies conveyed through these interactions and thus assume the encompassing predominant wildlife value orientation (Manfredo 2008). Naturally, while this is true on the aggregate level (i.e., for the average individual), a specific individual person's mental dispositions might diverge from dominant cultural ideas and ideologies. Wildlife value orientations exist at the micro-level (individuals) as mental dispositions reflecting general thought about wildlife.

The predominant wildlife value orientations as identified by researchers have been labeled as domination and mutualism (Jacobs et al. 2019; Manfredo et al. 2009). Domination oriented individuals believe wildlife should be managed for human benefits and tend to prioritize human well-being over wildlife well-being. Mutualism oriented people regard wildlife as belonging to an extended family and believe wildlife deserve care and rights (Jacobs et al. 2019; Manfredo 2008). Wildlife value orientations predict behavioral inten- 
tions regarding wildlife (Fulton et al. 1996); attitudes towards wildlife species or issues (Fulton et al. 1996; Teel and Manfredo 2010); acceptability of management actions (Jacobs et al. 2014b; Sijtsma et al. 2012; Whittaker et al. 2006; Zainal Abidin 2019; Zinn et al. 1998); conservation support (Hermann et al. 2013); and the influence of ecological information on preferences for landscapes that are beneficial for wildlife (Straka et al. 2016). Hence, wildlife value orientations inform more specific thought and behavior related to wildlife. Associated scales have been tested on samples of the general public in various Western countries, including Denmark (Gamborg and Jensen 2016), the Netherlands (Jacobs et al. 2014b) and the USA (Manfredo et al. 2009). In those studies (Gamborg and Jensen 2016; Jacobs et al. 2014b; Manfredo et al. 2009), and in studies examining specific segments of populations (Cerri et al. 2017; Hermann et al. 2013), reliability indices (evaluated as internal consistency of the domination and mutualism scales) were acceptable. These findings do not indicate to what extent the scales are reliable in other and, in particular, non-Western samples.

The concept of worldviews denotes sets of assumptions about physical and social reality (i.e., ideologies) that may have powerful effects on cognition and behavior (Koltko-Rivera 2004). Worldviews, constituted by webs of stories shared in a culture, describe the universe and life in terms of what is and what should be (Harari 2014). Worldviews give meaning to life. An influential model posits that the way people think about the relationship between humans and nature is one of the basic parts of worldviews (Kluckhohn 1949; Kluckhohn and Strodtbeck 1961). Wildlife value orientations, then, are part of a culture's worldview. Cultures exist on different scales, varying from local cultures to global culture (Lehman et al. 2004). Country is an important category in this respect, and cultures vary between them. Different countries often have different languages, laws, myths, histories, memes, customs, traditions, and forms of expression (Schwartz 1999). Indeed, research suggests that values and value orientations vary across countries (Hofstede 2001; Inglehart and Baker 2000; Schwartz 2006, 1999). Moreover, research shows that values are related to environmental attitudes and intentions (Bouman et al. 2020). Also, cross-cultural research revealed that values, as well as the association between values and environmental concepts, such as climate change perception and environmental responsibility, vary by country (Poortinga et al. 2019; Punzo et al. 2019). Consequently, examining differences in wildlife value orientations across countries presents a valuable way to expand our understanding of an important source of variation in wildlife value orientations.

The concepts of domination and mutualism do not necessarily cover all salient beliefs about wildlife in different, and in particular, non-Western countries. For instance, indigenous communities often depend on wildlife as a food source (Camino et al. 2018). At the same time, some of these communities have an animistic view of wildlife-believing animals have a spiritual essence just like humans (Camino et al. 2018; Harari 2014). This reflects an orientation that is different from both domination and mutualism. The present research does not involve indigenous communities, but this example does show that the question of whether the concepts of domination and mutualism apply to populations of non-Western countries is worth examining. The present research makes a contribution to this field of study.

Theory on changes in values on the collective level suggests that wildlife orientations are likely to vary between countries. As societies move from the industrial to the post-industrial phase, dominant values shift from an emphasis on material values (e.g., safety) to post- 
material values (e.g., belonging) (Inglehart 1997). In the context of human-wildlife relationships this extends to a shift from domination to mutualism (Manfredo et al. 2020, 2009). The shift is caused by the succession of generations. Value priorities change at the societal level as younger generations, raised in different societal conditions and shaped by different narratives, replace older generations. Typically, a higher GDP per capita is associated with more post-material values (Inglehart 1997; Inglehart and Baker 2000), and by extension with a less domination and more mutualist orientation to wildlife (Manfredo et al. 2020, 2009). Note, however, that this research pertains to aggregate figures on national levels or US-state levels, and hence relationships might be different in cultural communities at different levels, such as indigenous communities.

Previous research has revealed that wildlife value orientations vary according to demographics. Yet, demographic relationships with value orientations are not consistent across countries. In both the US and the Netherlands, men were more oriented towards domination than women; residents of rural areas were more domination orientated than those living in cities; and younger age groups were more mutualism oriented than older age groups (Manfredo et al. 2009; Vaske et al. 2011a). In Denmark, gender was the only demographic characteristic associated with wildlife value orientations, with women being more mutualism oriented than men (Gamborg and Jensen 2016). The differences in previous findings raise the question whether demographic associations with orientations vary across countries.

In human dimensions of wildlife research, differences in sampling strategies (e.g. visitor samples vs. random samples of a population) and measurements (e.g. different concepts and associated measurement scales) do not facilitate data-level cross-national comparisons of findings. Consequently, the literature raises the question of whether scientific insights into human-wildlife relationships are sample-specific or would generalize across populations (Tam and Milfont 2020). Lack of insight into population specificity of findings also hampers practitioners in estimating the relevance of existing knowledge on human-wildlife relationships in other conservation contexts. It makes it harder for them to consider and respond to cultural differences.

The present study uses convenience sampling techniques to obtain data from university students across seven countries, to advance understanding about the differences in ways of thinking about wildlife, across nations. Three research questions guided our research:

1. Does reliability of the wildlife value orientation scales vary across students from different countries?

2. Do relationships between demographics and wildlife value orientations vary across students from different countries?

3. Do wildlife value orientations vary across students from different countries?

\section{Methods}

\section{Sampling strategy}

Assuming that a global culture exists, driven by mass media, social media and internet messages, university students are one of the population segments that may experience its influence. Hence, student samples may be valuable for testing cross-cultural differences across 
countries. This argument rests on several findings from previous research. First, students are typically at an age at which their formative years are coming to an end, and hence their wildlife value orientations are likely to have stabilized (Decker et al. 2012). Thus, students are the first generational cohort to have stable orientations that have been shaped under the most recent societal conditions. Furthermore, today's students are likely to become tomorrow's leaders, influencing the course of both policy and practice (Straka et al. 2020). Moreover, obtaining student samples provides a convenient sampling alternative for researchers (Rad et al. 2018), often employed for social science that is conducted within budget constraints (Henrich et al. 2010). In fact, convenience samples, including student samples, have been recommended for early theory testing ( $\mathrm{Rad}$ et al. 2018), as a valuable mechanism to help validate the potential value of allocating substantial resources to representative samples, in subsequent research. When gauging the feasibility of using student samples, it is important to consider the type of research questions being asked (Gächter 2010). In the case of the current study, the research questions explored relationships between concepts. Our inquiry did not require that samples were representative of entire populations; thus, we chose specific samples of college students, taken from comparable segments of populations, across seven countries.

\section{Samples}

Questionnaires were distributed among university students in Australia, Canada, Germany, Japan, Malaysia, the Netherlands and Serbia (Fig. 1). In all countries except Australia, paper and pencil questionnaires were given to students during breaks between classes. These were either collected in the next class or the students were given the opportunity to fill the survey out during class. In Australia, students were invited via email to complete an online questionnaire, which was accessible for two weeks. Students were from the following specific universities: Deakin University in Melbourne (Australia); University of British Colum-

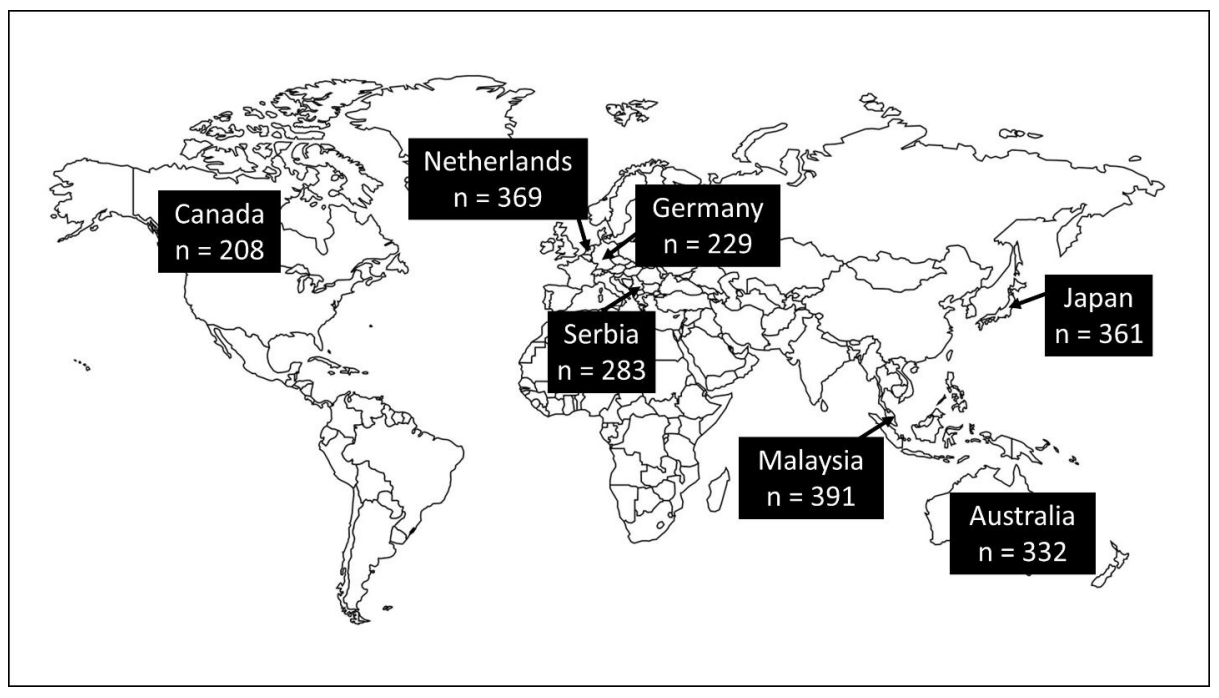

Fig. 1 Sample distribution and sizes 
bia in Vancouver (Canada); Ludwig Maximilian University in Munich (Germany); Tokyo Metropolitan University (Japan); University Putra Malaysia in Kuala Lumpur (Malaysia); Wageningen University (the Netherlands); and University of Belgrade (Serbia). The present dataset gradually emerged over the years 2013-2017 (see Table 1 for exact year and sample specifics per country). The first author developed the survey for a Dutch master thesis project. The survey was subsequently used in PhD projects in Canada and Malaysia. At the next stage, colleagues were approached in Japan, Serbia, Australia and Germany. The invitations were made with the purpose of establishing a dataset for comparisons across countries.

Potential respondents were informed that participation was strictly voluntary, that responses would be treated confidentially and anonymously, and that data would be used on an aggregate level for scientific publications.

Wildlife value orientations might vary across students in different domains of science. For instance, students in the environmental sciences might think differently about wildlife than students in many other domains. Not all academic study domains are represented at Wageningen University (for instance, no liberal arts curricula currently exist at this university). To keep the sampling strategy consistent across universities, we sampled students from the natural sciences, social sciences and environmental sciences, as these are part of all seven universities. In the results section we will use the word "students" to refer to this specific sample.

\section{Measurement instrument}

We applied the standard and widely used 19 item scales (e.g., Gamborg and Jensen 2016; Jacobs et al. 2014b; Teel and Manfredo 2010; Zainal Abidin and Jacobs 2016) to measure wildlife value orientations (see Table 2 for specific items). The scales for domination consist of appropriate use beliefs ( 6 items) and hunting beliefs ( 4 items). The scales for mutualism consist of social affiliation beliefs ( 4 items) and caring beliefs ( 5 items). Items were coded on seven-point scales ( -3 "strongly disagree" to +3 "strongly agree", with 0 as a neutral point). In addition, we included measures of acceptance of different wildlife management actions, also coded on seven-point scales. These measures are outside the scope of the present paper that focusses on differences across countries. The data will be used in future analyses to estimate the predictive potential of wildlife value orientations for more specific and contextual attitudes. The questionnaire included items to assess gender; whether students grew up raised in rural or urban settings (10,000 inhabitants as cut-off point); and whether students attended a natural science, environmental science or social science curriculum.

Table 1 Sample characteristics

\begin{tabular}{llllllll}
\hline & Sample size & Female \% & Male \% & Rural \% & Urban \% & Response rate \% & Year \\
\hline Australia & 332 & 71 & 29 & 34 & 66 & 13 & 2017 \\
Canada & 208 & 59 & 41 & 13 & 87 & 94 & 2013 \\
Germany & 229 & 47 & 53 & 38 & 62 & 85 & 2016 \\
Japan & 361 & 44 & 56 & 5 & 95 & 89 & 74 \\
Malaysia & 391 & 76 & 24 & 43 & 57 & 69 & 2016 \\
Netherlands & 369 & 64 & 36 & 27 & 73 & 100 & 2013 \\
Serbia & 283 & 55 & 45 & 19 & 81 & & 2017 \\
Total & 2174 & 60 & 40 & 26 & 74 & & \\
\hline
\end{tabular}


Finally, a screening question was used to identify students that were national residents of the sampled countries (in contrast to international visiting students). The survey was preceded by a short explanation of the study purpose, data confidentially and anonymity, and the following definition of wildlife: animals who are living freely in the wild. Questionnaires were translated into German, Japanese, Malay, Dutch, and Serbian. At all universities except Australia, approval by an ethics committee was not needed. At Wageningen University, for example, the ethics committee's answers to screening questions suggested that there was no need for specific approval. In Australia, approval was requested and granted by the ethics committee (project number STEC-04-2015-MILLER-MOD 02).

\section{Data analysis}

We performed reliability analyses to evaluate if intended items could be assumed to measure a latent construct (i.e., a basic belief). Reliability analysis is recommended (Vaske 2008) when theory suggests how items should group together in relation to concepts. The analysis included Cronbach's Alpha to estimate internal consistency among items and item-total correlations to see how well a single item fits within the latent construct. These analyses were conducted separately for each country, to respond to the first research question.

Independent samples t-tests were performed within each country with gender and urban versus rural upbringing as independent variables, and domination and mutualism as dependent variables. Typically, t-tests are recommended for comparing two groups (Vaske 2008). Cohen's $d$ is the recommended associated effect size index (Vaske 2008). These analyses were also performed separately for each country, to respond to the second research question.

To respond to the third research question - estimating differences across countrieschecking for demographics is important. For instance, if the percentage of men in the sample of one country is larger than in the sample of another country, and men are in general more domination oriented than women, a difference in domination between the countries might be due to sample differences rather than differences between countries. General linear models allow for group differences to be estimated while checking for demographics (Diez-Roux 2000). As an alternative, multilevel analysis is often recommended to simultaneously address group-level and individual-level factors (Diez-Roux 2000). The application of multilevel modeling in conservation social science is limited (Manfredo et al. 2009). The type of inferences that can be drawn are different between single level and multilevel models. If estimating significant differences using a single level model, one can conclude that differences exist between the specific groups for which data are collected. If estimating significant differences using a multilevel model, the estimation can be generalized: Assuming the groups (e.g., a selection of countries) are sampled from a population of groups (all countries in the world), significant differences would imply that in general, there are differences (between countries) (Bryan and Jenkins 2015; Diez-Roux 2000). Requirements for single level and multilevel models are different. For instance, for multilevel models, a particular number of groups (e.g. countries) is required for sufficient statistical power. While there is no golden standard, 10 groups is sometimes indicated as desirable (Nezlek 2008), although other sources suggest a higher (Kreft and De Leeuw 1998) or lower (Stegmueller 2013) minimum number of groups. As there is no strict guideline for the minimum number of groups, the present study will use both single level and multilevel models to estimate 
whether cultural differences exist between the specific countries investigated, and whether generalized inferences are justified.

We used N-way ANOVA as the single level analysis strategy to estimate differences in individuals' wildlife value orientations across countries while correcting for rural or urban background and gender (i.e., $7 * 2 * 2$ ANOVA). As another strategy, multilevel modelling was used to estimate the effect of country (group level variable) on wildlife value orientations. Initially, we tested six models for both domination and mutualism. The null model had no predictors. Model 1 added country as a group-level variable as a predictor. Model 2 added rural or urban background as an individual level variable as fixed effect (assuming its influence is the same within different countries). Model 3 added a random co-efficient for rural or urban background (allowing its influence of to vary across countries). Model 4 added gender as a fixed effect, and model 5 added a random co-efficient for gender. Likelihood ratio tests indicated that each subsequent model statistically fitted the data significantly better than the previous one (e.g., comparing model 5 to model 4) for both domination and mutualism. This means that the model estimating the effect of country and controlling for rural or urban background and gender while allowing these effects to vary across countries was superior to all other models. We present the full models in the results section. In addition to these models, we tested models with study domain (i.e., natural sciences, environmental sciences, social sciences) as fixed and random effects, but these models were statistically inferior to model 5. The Intra-Class Coefficient (ICC) was used to estimate the percentage of variance explained by country. Domination and mutualism were grand mean standardized (i.e., mean $=0$ and standard deviation $=1$ ) prior to the N-way ANOVA and the multilevel analyses. All analyses were performed with IBM SPSS Statistics 25.

\section{Results}

\section{Scale reliability within countries (research question 1)}

Internal consistency was acceptable against the frequently accepted cut-off point of 0.65 (Vaske 2008) for all basic beliefs of students in all countries, except for hunting beliefs among Japanese students (Table 2). Against a more rigorous standard of 0.70 (Field 2013), 25 out of 28 indices suggest acceptable reliability. The three figures under the threshold pertain to appropriate use beliefs of Serbian students, and hunting beliefs of Japanese and Malaysian students. For each basic belief, the lowest internal consistency was observed in students from a non-Western country, except for caring beliefs, for which all indices indicate adequate internal consistency by all standards. Also, item-total correlations for hunting items were lower for students in Japan and Malaysia than in other countries.

Based on the reliability indices, we computed composite indices for each basic belief as the mean of the underlying items. Subsequently, we computed composite indices for domination (mean of appropriate use and hunting) and mutualism (mean of social affiliation and caring). The latter indices were used for all subsequent analyses reported in this paper. 
Table 2 Internal consistency indices (Cronbach's Alpha) of wildlife basic beliefs scales (printed bold) and item-total correlations of associated items (not bold)

\begin{tabular}{|c|c|c|c|c|c|c|c|}
\hline & Australia & Canada & Germany & Japan & Malaysia & Netherl. & Serbia \\
\hline $\begin{array}{l}\text { Appropriate use (Cron- } \\
\text { bach's Alpha) }\end{array}$ & 0.78 & 0.77 & 0.76 & 0.80 & 0.72 & 0.76 & 0.66 \\
\hline $\begin{array}{l}\text { Humans should manage fish } \\
\text { and wildlife populations so } \\
\text { that humans benefit. }\end{array}$ & 0.54 & 0.50 & 0.48 & 0.57 & 0.28 & 0.43 & 0.39 \\
\hline $\begin{array}{l}\text { The needs of humans should } \\
\text { take priority over fish and } \\
\text { wildlife protection. }\end{array}$ & 0.58 & 0.61 & 0.59 & 0.62 & 0.40 & 0.54 & 0.29 \\
\hline $\begin{array}{l}\text { It is acceptable for people to } \\
\text { kill wildlife if they think it } \\
\text { poses a threat to their life. }\end{array}$ & 0.59 & 0.44 & 0.51 & 0.62 & 0.54 & 0.56 & 0.33 \\
\hline $\begin{array}{l}\text { It is acceptable for people } \\
\text { to kill wildlife if they think } \\
\text { it poses a threat to their } \\
\text { property. }\end{array}$ & 0.63 & 0.59 & 0.58 & 0.68 & 0.56 & 0.61 & 0.52 \\
\hline $\begin{array}{l}\text { It is acceptable to use fish } \\
\text { and wildlife in research even } \\
\text { if it may harm or kill some } \\
\text { animals. }\end{array}$ & 0.48 & 0.51 & 0.47 & 0.58 & 0.46 & 0.37 & 0.36 \\
\hline $\begin{array}{l}\text { Fish and wildlife are on earth } \\
\text { primarily for people to use. }\end{array}$ & 0.41 & 0.46 & 0.36 & 0.29 & 0.48 & 0.56 & 0.47 \\
\hline $\begin{array}{l}\text { Hunting (Cronbach's } \\
\text { Alpha) }\end{array}$ & 0.82 & 0.74 & 0.71 & 0.54 & 0.65 & 0.74 & 0.80 \\
\hline $\begin{array}{l}\text { We should strive for a world } \\
\text { where there's an abundance of } \\
\text { fish and wildlife for hunting } \\
\text { and fishing. }\end{array}$ & 0.52 & 0.38 & 0.40 & 0.24 & 0.29 & 0.26 & 0.55 \\
\hline $\begin{array}{l}\text { Hunting is cruel and inhu- } \\
\text { mane to the animals. }\end{array}$ & 0.72 & 0.64 & 0.52 & 0.40 & 0.49 & 0.69 & 0.69 \\
\hline $\begin{array}{l}\text { Hunting does not respect the } \\
\text { lives of animals. }\end{array}$ & 0.72 & 0.68 & 0.59 & 0.45 & 0.57 & 0.68 & 0.68 \\
\hline $\begin{array}{l}\text { People who want to hunt } \\
\text { should be provided the op- } \\
\text { portunity to do so. }\end{array}$ & 0.63 & 0.47 & 0.48 & 0.22 & 0.38 & 0.54 & 0.51 \\
\hline $\begin{array}{l}\text { Social affiliation (Cron- } \\
\text { bach's Alpha) }\end{array}$ & 0.81 & 0.83 & 0.80 & 0.76 & 0.74 & 0.80 & 0.78 \\
\hline $\begin{array}{l}\text { We should strive for a world } \\
\text { where humans and fish and } \\
\text { wildlife can live side by side } \\
\text { without fear. }\end{array}$ & 0.52 & 0.52 & 0.46 & 0.37 & 0.47 & 0.45 & 0.44 \\
\hline $\begin{array}{l}\text { I view all living things as part } \\
\text { of one big family. }\end{array}$ & 0.72 & 0.72 & 0.66 & 0.64 & 0.66 & 0.70 & 0.59 \\
\hline $\begin{array}{l}\text { Animals should have rights } \\
\text { similar to the rights of } \\
\text { humans. }\end{array}$ & 0.65 & 0.68 & 0.64 & 0.56 & 0.46 & 0.66 & 0.65 \\
\hline $\begin{array}{l}\text { Wildlife are like my family } \\
\text { and I want to protect them. }\end{array}$ & 0.65 & 0.71 & 0.69 & 0.68 & 0.55 & 0.67 & 0.69 \\
\hline Caring (Cronbach's Alpha) & 0.86 & 0.86 & 0.88 & 0.83 & 0.88 & 0.84 & 0.86 \\
\hline $\begin{array}{l}\text { I care about animals as much } \\
\text { as I do other people. }\end{array}$ & 0.66 & 0.63 & 0.69 & 0.64 & 0.66 & 0.67 & 0.66 \\
\hline $\begin{array}{l}\text { It would be more rewarding } \\
\text { to me to help animals rather } \\
\text { than people. }\end{array}$ & 0.61 & 0.65 & 0.55 & 0.40 & 0.59 & 0.66 & 0.61 \\
\hline
\end{tabular}


Table 2 (continued)

\begin{tabular}{llllllll}
\hline & Australia & Canada & Germany & Japan & Malaysia & Netherl. & Serbia \\
\hline $\begin{array}{l}\text { I take great comfort in the } \\
\text { relationships I have with } \\
\text { animals. }\end{array}$ & 0.77 & 0.71 & 0.77 & 0.61 & 0.77 & 0.52 & 0.75 \\
$\begin{array}{l}\text { I feel a strong emotional bond } \\
\text { with animals. }\end{array}$ & 0.77 & 0.78 & 0.81 & 0.80 & 0.78 & 0.74 & 0.75 \\
$\begin{array}{l}\text { I value the sense of com- } \\
\text { panionship I receive from } \\
\text { animals. }\end{array}$ & 0.71 & 0.69 & 0.76 & 0.73 & 0.77 & 0.66 & 0.63 \\
\hline
\end{tabular}

\section{Demographic differences within countries (research question 2)}

Differences between female and male students for domination (Table 3) and mutualism (Table 4) were larger than differences between students raised in rural areas and students raised in urban areas. In all countries except Serbia, female students tended to be less domination oriented than male students. In Serbia, the effect was the other way around. Also, female students tended to be more mutualism oriented than male students in all countries except Serbia (men more mutualism oriented) and Malaysia (no difference observed). Urban versus rural upbringing was not associated with wildlife value orientations of students in the majority of the studied countries, though we did find small effects in three countries.

\section{Differences in wildlife value orientations between countries (research question 3)}

Descriptive figures suggest that students in Serbia were more domination oriented (mean $=0.41)$ and less mutualism orientated (mean $=-0.69)$ than students in other countries (Table 5). Students in Australia were less domination orientated (mean $=-1.11$ ) and

Table 3 Demographic differences in domination within countries as estimated by independent samples $t$-tests 1

\begin{tabular}{|c|c|c|c|c|c|c|c|c|}
\hline & \multicolumn{4}{|l|}{ Gender } & \multicolumn{4}{|c|}{ Urban versus rural residency } \\
\hline & $\begin{array}{l}\text { Mean } \\
\text { females }\end{array}$ & $\begin{array}{l}\text { Mean } \\
\text { Males }\end{array}$ & t-value & $\begin{array}{l}\text { Co- } \\
\text { hen's } \\
d\end{array}$ & $\begin{array}{l}\text { Mean } \\
\text { Rural }\end{array}$ & $\begin{array}{l}\text { Mean } \\
\text { Urban }\end{array}$ & t-value & $\begin{array}{l}\text { Co- } \\
\text { hen's } \\
d\end{array}$ \\
\hline Australia & -1.31 & -0.51 & $5.18^{* * *}$ & 0.69 & -0.75 & -1.19 & $2.76^{* *}$ & 0.37 \\
\hline Canada & -0.65 & 0.29 & $7.31^{* * * *}$ & 1.03 & -0.44 & -0.24 & $\begin{array}{l}-0.98 \\
\text { (n.s.) }\end{array}$ & 0.21 \\
\hline Germany & -0.98 & -0.24 & $5.66^{* * * *}$ & 0.76 & -0.57 & -0.58 & $\begin{array}{l}0.09 \\
\text { (n.s.) }\end{array}$ & 0.01 \\
\hline Japan & -0.53 & -0.01 & $6.27^{* * * *}$ & 0.52 & -0.03 & -0.24 & $\begin{array}{l}0.69 \\
\text { (n.s.) }\end{array}$ & 0.21 \\
\hline Malaysia & -0.45 & -0.05 & $3.75^{* * * *}$ & 0.44 & -0.37 & -0.31 & $\begin{array}{l}-0.63 \\
\text { (n.s.) }\end{array}$ & 0.07 \\
\hline Netherlands & -0.50 & 0.07 & $5.59^{* * * *}$ & 0.61 & -0.04 & -0.39 & $3.03^{* *}$ & 0.36 \\
\hline Serbia & 0.83 & -0.12 & $-7.97^{* * *}$ & 0.95 & 0.01 & 0.50 & $-2.84^{* *}$ & 0.45 \\
\hline
\end{tabular}

${ }^{1}$ Figures present means on a scale from -3 (disagree very much) to +3 (agree very much) with 0 as a neutral point

${ }^{* * *}$ Significant at $p<0.01$; ${ }^{* * *}$ Significant at $p<0.001$; (n.s.) Not significant 
Table 4 Demographic differences in mutualism within countries as estimated by independent samples $t$-tests 1

\begin{tabular}{|c|c|c|c|c|c|c|c|c|}
\hline & \multicolumn{4}{|c|}{ Gender differences } & \multicolumn{4}{|c|}{$\begin{array}{l}\text { Urban versus rural residency } \\
\text { differences }\end{array}$} \\
\hline & $\begin{array}{l}\text { Mean } \\
\text { females }\end{array}$ & $\begin{array}{l}\text { Mean } \\
\text { males }\end{array}$ & t-value & $\begin{array}{l}\text { Co- } \\
\text { hen's } \\
d\end{array}$ & $\begin{array}{l}\text { Mean } \\
\text { rural }\end{array}$ & $\begin{array}{l}\text { Mean } \\
\text { urban }\end{array}$ & t-value & $\begin{array}{l}\text { Co- } \\
\text { hen's } \\
d\end{array}$ \\
\hline Australia & 1.91 & 1.23 & $-4.39^{* * *}$ & 0.60 & 1.59 & 1.73 & $\begin{array}{l}-1.01 \\
\text { (n.s.) }\end{array}$ & 0.13 \\
\hline Canada & 1.54 & 0.64 & $-6.30^{* * *}$ & 0.88 & 1.58 & 1.10 & $2.11^{*}$ & 0.44 \\
\hline Germany & 0.50 & -0.29 & $-4.67^{* * *}$ & 0.62 & 0.27 & -0.06 & 1.80 (n.s.) & 0.25 \\
\hline Japan & 0.06 & -0.19 & $-2.29^{*}$ & 0.24 & -0.11 & -0.08 & $\begin{array}{l}-0.11 \\
\text { (n.s.) }\end{array}$ & 0.03 \\
\hline Malaysia & 1.17 & 1.20 & $\begin{array}{l}0.27 \\
\text { (n.s.) }\end{array}$ & 0,06 & 1.09 & 1.26 & $\begin{array}{l}-1.67 \\
\text { (n.s.) }\end{array}$ & 0.17 \\
\hline Netherlands & 0.15 & -0.24 & $-3.02^{* *}$ & 0.33 & -0.22 & 0.09 & $\begin{array}{l}-2.22 \\
\text { (n.s.) }\end{array}$ & 0.28 \\
\hline Serbia & -0.98 & -0.33 & $4.32^{* * *}$ & 0.52 & -0.33 & -0.78 & 2.20 (n.s.) & 0.36 \\
\hline
\end{tabular}

${ }^{1}$ Figures present means on a scale from -3 (disagree very much) to +3 (agree very much) with 0 as a neutral point

${ }^{*}$ Significant at $p<0.05 ;{ }^{* *}$ Significant at $p<0.01 ;{ }^{* * *}$ Significant at $p<0.001$; (n.s.) Not significant

Table 5 Wildlife value orientations and associated basic beliefs in samples in seven countries1

\begin{tabular}{llllllll}
\hline & Australia & Canada & Germany & Japan & Malaysia & Netherl. & Serbia \\
\hline Domination & $\mathbf{- 1 . 1 1}$ & $\mathbf{- 0 . 2 6}$ & $\mathbf{- 0 . 5 7}$ & $\mathbf{- 0 . 2 5}$ & $\mathbf{- 0 . 3 4}$ & $\mathbf{- 0 . 3 0}$ & $\mathbf{0 . 4 1}$ \\
& $\mathbf{( 1 . 1 6 )}$ & $\mathbf{( 1 . 0 2 )}$ & $\mathbf{( 1 . 0 4 )}$ & $\mathbf{( 0 . 8 2 )}$ & $\mathbf{( 0 . 9 0 )}$ & $\mathbf{( 0 . 9 7 )}$ & $\mathbf{( 1 . 1 0 )}$ \\
Appropriate use & -1.36 & -0.73 & -0.93 & -0.75 & 0.32 & -0.58 & 0.48 \\
Hunting & -0.85 & 0.21 & -0.20 & 0.26 & -1.00 & -0.01 & 0.34 \\
Mutualism & $\mathbf{1 . 7 3}$ & $\mathbf{1 . 1 6}$ & $\mathbf{0 . 0 7}$ & $\mathbf{- 0 . 0 9}$ & $\mathbf{1 . 1 9}$ & $\mathbf{0 . 0 0}$ & $\mathbf{- 0 . 6 9}$ \\
& $\mathbf{( 1 . 0 8 )}$ & $\mathbf{( 1 . 1 1 )}$ & $\mathbf{( 1 . 3 3 )}$ & $\mathbf{( 1 . 0 6 )}$ & $\mathbf{( 1 . 0 0 )}$ & $\mathbf{( 1 . 1 8 )}$ & $\mathbf{( 1 . 3 0 )}$ \\
Social affiliation & 1.64 & 1.15 & 0.44 & -0.12 & 1.36 & -0.25 & -0.56 \\
Caring & 1.82 & 1.18 & -0.30 & -0.05 & 1.02 & 0.26 & -0.81 \\
\hline
\end{tabular}

${ }^{1}$ Figures present means on a scale from -3 (disagree very much) to +3 (agree very much) with 0 as a neutral point, and standard deviations (between brackets) for the two value orientations

more mutualism oriented (mean $=1.73)$ than students in other countries. For domination, the results for students in all the other studied countries were similar. The means for mutualism among students were close to neutral in Germany, Japan and the Netherlands, while these were more than one scale-point higher in Canada and Malaysia. Differences for mutualism (more than 2.5 scale-points between students in Serbia and Australia) were larger than differences for domination (more than 1.5 scale-points).

Findings on the level of basic beliefs about wildlife point to differences that are not visible in the aggregated wildlife value orientation figures. For instance, the mean for mutualism was practically the same in the German and Dutch student samples. Yet, the ways these similar means were constituted differ. The German students felt more socially affiliated with wildlife than the Dutch students, while the Dutch students believed that wildlife deserves care more than the German students. Similarly, the means for domination were about the same in the Canadian and Malaysian student samples, while the means were different for both underlying beliefs about appropriate use and hunting (Table 5). 
$\mathrm{N}$-way ANOVA models indicate that wildlife value orientations of students were different across the sampled countries, controlling for rural/urban background and gender (Table 6). The effect of country was larger for mutualism ( $21 \%$ explained variance, as indicated by Partial $\eta^{2}$ ) than for domination (6\%). Moreover, for both domination and mutualism, the effect of country was larger than any other direct or interaction effect. Gender, the interaction between country and rural/urban background, and the interaction between country and gender were associated with wildlife value orientations of students.

Multilevel analyses figures suggest the effect of country on domination (5\% explained variation, ICC in Table 7) was not significant ( $p=0.19)$, controlling for rural/urban background and gender, allowing these effects to vary across countries. This implies that based on the present data, we cannot safely conclude that in general, systematic differences in domination exist across students in different countries. The fixed and random effects for gender were marginally significant, suggesting it is likely that an overall gender effect exists, and that the effects of gender vary across students in different countries. For mutualism, the effect ( $23 \%$ explained variance) was marginally significant $(p=0.08)$, tentatively indicating systematic cultural differences in mutualism exist across students in different countries. The fixed effect of gender was not significant, while the random effect was marginally significant $(p=0.09)$.

Table 6 N-way ANOVA models estimating differences in wildlife value orientations across countries

\begin{tabular}{lllllll}
\hline & \multicolumn{5}{l}{ Domination } & \multicolumn{5}{l}{ Mutualism } \\
\hline Parameters & Partial $\eta 2$ & $F$-value (df) & $p$-value & Partial $\eta 2$ & $F$-value (df) & $p$-value \\
Intercept & $<0.01$ & $5.94(1)$ & 0.01 & $<0.01$ & $0.41(1)$ & 0.53 \\
Country & 0.06 & $20.39(6)$ & $<0.001$ & 0.21 & $89.87(6)$ & $<0.001$ \\
Residence & $<0.01$ & $1.71(1)$ & 0.19 & $<0.01$ & $0.30(1)$ & 0.58 \\
Gender & 0.03 & $52.01(1)$ & $<0.001$ & 0.01 & $20.55(1)$ & $<0.001$ \\
Country*Residence & 0.02 & $5.99(6)$ & $<0.001$ & 0.01 & $3.84(6)$ & 0.001 \\
Country*Gender & 0.05 & $18.70(6)$ & $<0.001$ & 0.03 & $9.99(6)$ & $<0.001$ \\
Residence*Gender & $<0.01$ & $<0.01(1)$ & 0.96 & $<0.01$ & $0.01(1)$ & 0.91 \\
Country*Residence*Gender & 0.01 & $1.62(6)$ & 0.14 & 0.01 & $1.94(6)$ & 0.07 \\
Corrected model & 0.24 & $24.15(27)$ & $<0.001$ & 0.37 & $43.45(27)$ & $<0.001$ \\
\hline
\end{tabular}

Table 7 Multilevel models estimating differences in wildlife value orientations across countries

\begin{tabular}{llllllll}
\hline & \multicolumn{3}{c}{ Domination } & \multicolumn{5}{c}{ Mutualism } \\
\hline Parameters & & Beta & Standard Error & $p$-value & Beta & Standard Error & $p$-value \\
Fixed & Intercept & 0.31 & 0.09 & 0.01 & -0.13 & 0.17 & 0.47 \\
& Residence & -0.08 & 0.10 & 0.46 & -0.03 & 0.08 & 0.74 \\
& Gender & -0.40 & 0.20 & 0.09 & 0.24 & 0.13 & 0.12 \\
Variance & Country & 0.04 & 0.03 & 0.19 & 0.19 & 0.11 & 0.08 \\
& Residence & 0.05 & 0.04 & 0.15 & 0.03 & 0.02 & 0.23 \\
& Gender & 0.29 & 0.16 & 0.07 & 0.12 & 0.07 & 0.09 \\
ICC & Residual & 0.74 & 0.02 & $<0.001$ & 0.63 & 0.02 & $<0.001$ \\
$-2 \mathrm{LL}$ & & 0.05 & & & 0.23 & & \\
\hline
\end{tabular}




\section{Discussion}

This study examined cross-cultural differences in wildlife value orientations, using samples of university students in seven countries.

\section{Reliability of wildlife value orientation scales}

Internal consistencies of the basic wildlife belief scales suggest adequate reliability as an overall pattern (research question 1). The lowest consistency indices were found for students in non-Western countries. Indices across countries were in a relatively narrow range except for the hunting basic belief (Table 2). Therefore, we believe the figures do not suggest considerable differences in scale reliability across student samples from different countries.

However, the figures do not imply that the four measured basic beliefs cover all salient beliefs about wildlife in all samples. Other beliefs about wildlife and their management, not covered by the scales, might exist in some countries. For instance, qualitative research suggests that many Malaysians believe that humans and wildlife belong to different and separate geographical domains (Zainal Abidin 2019). A quantitative follow-up study was conducted, adding items to assess the geographical separation belief to the existing 19 wildlife value orientation items (Table 2). The results of this study suggested no improvement in terms of predictive potential for acceptability of management interventions or support for conservation (Zainal Abidin 2019). As another example, animistic beliefs about wildlife could be important to adequately assess orientations in indigenous communities (Camino et al. 2018; Harari 2014).

Lower internal consistencies might be caused by a different structure of basic beliefs than the underlying theory would suggest. For example, an exploratory factor analysis of the hunting items in a pilot study in Malaysia suggested that there may be two dimensions of hunting basic beliefs, labeled as consequences for humans and consequences for animals (Zainal Abidin and Jacobs 2016). Additional exploratory factor analyses of the four hunting belief items revealed that the same two dimensions also emerged in the present Malaysian and Japanese student samples. The items "hunting is inhumane and cruel to animals" and "hunting does not respect the lives of animals" (see Table 2) constitute hunting beliefs about consequences for animals. The items "we should strive for a world where there is an abundance of fish and wildlife for hunting and fishing" and "people who want to hunt should be provided the opportunity to do so" constitute hunting beliefs about consequences for humans. In all other countries, the hunting beliefs consisted of one dimension (as exploratory factor analyses suggest only one factor with Eigenvalue $>1$ ). Overall, though, the figures imply that the measurement was fairly stable across the student samples of different countries. This finding suggests the concept of wildlife value orientations and the associated scales would be feasible for future cross-national comparative research.

\section{Relationships between demographics and wildlife value orientations}

Differences in student samples across countries were identified in the relationships between demographics and wildlife value orientations (research question 2). In all countries except one, women were less oriented towards domination than men. In Serbia, it was the other way around. Female students were more mutualism oriented than male students in the majority 
of the studied countries, except for Serbia (reverse relationship) and Malaysia (no relationship). Differences between students raised in urban or rural areas were smaller than gender differences, and not significant in most countries. Why female students in Serbia were more domination oriented and less mutualism oriented than male students is not obvious. We performed ancillary analyses to check whether this result might be a consequence of sample specifics. Male students were overrepresented in forestry in the Serbian sample. And forestry students were relatively less oriented towards domination and more towards mutualism than the other Serbian students. However, also within the other study domains, Serbian male students were less domination and more mutualism oriented than female students. There is another potential explanation: longitudinal research demonstrates that traditionalist and patriarchic orientations have persisted in Serbia after the collapse of communist Yugoslavia (Pešić 2006). Perhaps, in patriarchic societies, women feel less empowered than men, and are therefore more inclined to adhere to traditionalist values, in this case translating into a strong domination orientation to wildlife. Whatever the cause, the relationship is different from other countries in this study as well as in previous research (Gamborg and Jensen 2016; Manfredo et al. 2009; Vaske et al. 2011a). We cannot blindly generalize previous research to other countries, assuming that men in general are more domination oriented than women. By extension, this study illustrates that relationships between demographics and thought about wildlife can vary across cultures. To find out whether and which relationships exist in a given country, empirical studies will be needed.

The observed demographic differences also show how important it is to correct for demographics when estimating differences across countries. For instance, $44 \%$ of the students in the Japanese sample were women, while $70 \%$ of the students in the Australian sample were women. As male students were more domination oriented than female students in both countries (Tables 3 and 4), overrepresentation of female students in Australia might explain a part of the variation in students across countries. Not correcting for the gender effect might then lead to incorrect inferences about differences.

\section{Differences in wildlife value orientations across countries}

Country explained $6 \%$ of the variation in domination and $21 \%$ of the variation in mutualism $(p$ 's $<0.001)$ among the sampled students, as estimated with ANOVA. These findings indicate that there are differences in wildlife value orientations among students across the seven countries sampled in this study (research question 3). Importantly, the figures reflect differences in wildlife value orientations on the micro level of individuals, as basic beliefs that give meaning and direction to fundamental values in the context of human-wildlife relationships. Serbian students stood out as much more domination oriented and less mutualism oriented than those in other countries. However, also Australian students stood out (more mutualism and less domination oriented). Students in Malaysia and Canada were close together, as were students in Germany, Japan and the Netherlands. The Australian sampling method was different from the method in the other countries (invitation via email to respond to an online survey versus paper questionnaires handed out in class). Sampling methods can influence response as has also been demonstrated in research on wildlife value orientations (Vaske et al. 2011b). The relatively low response rate in Australia may have resulted in self-selection. Students who feel more compassion towards wildlife may have 
been more motivated to respond, perhaps causing over-representation of more mutualismoriented students.

Similar wildlife value orientations between countries do not necessarily mean similar thinking about wildlife. Findings on the level of specific basic beliefs about wildlife suggest differences that are not visible in the aggregated wildlife value orientation figures. For instance, the mean for mutualism was practically the same in the German and Dutch samples. Yet, the ways these similar means were constituted differ. The German students felt more socially affiliated with wildlife than the Dutch, while the Dutch believed more strongly than the Germans did that wildlife deserves care (Table 5). Similarly, means for domination were about the same in the Canadian and Malaysian samples, while the means were different for both underlying beliefs about appropriate use and hunting (Table 5). We recommend that future research on wildlife value orientations presents figures pertaining to basic beliefs as well, next to figures for wildlife value orientations.

Multilevel analyses estimated almost the same effect sizes as ANOVA did. Yet the $p$-values suggest these effects were not significant. This means that the present data do not support the conclusion that, in general, wildlife value orientations as cultural ideologies vary across countries (the macro level categorization used in this research). Technically, with seven countries, the group level sample size is small for constituting adequate statistical power needed to draw inferences about all countries (Kreft and De Leeuw 1998; Nezlek 2008; Stegmueller 2013). Furthermore, the sample was not randomly drawn from all countries, as would be a requirement to be met in order to draw generalized conclusions (Bryan and Jenkins 2015). In ANOVA, the individuals are the data points for estimating the effect of country, while in multilevel analysis, countries are the data points. An important tradeoff to be considered in future research is between the type of inferences one wants to make (sample specific or transcending) and the efforts (e.g. time and budget) that are needed (Bryan and Jenkins 2015). In addition, including samples of South-American and African countries would make the sample more representative at the global level. Another consideration is that multilevel modeling, and hence a larger number of groups, is also needed when the aim is to include group-level predictors. For example, research in the USA identified associations between wildlife value orientations and state-level predictors such as GDP per capita (Manfredo et al. 2020; Manfredo et al. 2009). Ancillary analyses using the present data suggest a marginally significant association between GDP per capita (as reported by UN data) and mean domination among the sampled students per country $(r=-0.73$, $p=0.06)$, but do not identify a relationship between GDP and mutualism $(r=0.39, p=0.38)$. Seven data points for these analyses is not enough for robust estimations. Yet, both effect sizes are in line with the direction of societal shifts toward post-material values (Inglehart 1997; Inglehart and Baker 2000), as well as previous findings pertaining to wildlife value orientations (Manfredo et al. 2020, 2009).

The difference between the effect sizes of country on domination ( $6 \%$ explained variance) and mutualism (21\%) in students was considerable and also visible in the descriptive figures (Table 5). Some figures shed light on this difference. Internal consistency figures of mutualism were superior to those of domination (Table 1). Hence, the measurement of domination introduces more noise than the measurement of mutualism. Noise might have suppressed the effect size. Also, the effect sizes of demographics on domination were larger than the effect sizes of demographics on mutualism (Tables 3 and 4). In other words, demographics explained a bigger portion of variance both as direct predictors and as part of inter- 
actions of domination relative to mutualism (Tables 6 and 7). Still, it is hard to imagine that these patterns would fully explain the large difference in effect sizes. This difference is even more remarkable when compared to similar figures in a USA study (Manfredo et al. 2009), suggesting that variation between states was $5.5 \%$ of the total variance for domination and $1.8 \%$ of the total variance for mutualism. The effect for domination is similar to the effect in the present study. For mutualism, however, the effect is much larger (over a factor ten) in the present study. It is hard to compare, on the level of data, findings of different states of one country in the general population with findings of different countries in students. Conceptually however, the comparison underlines the importance of cross-cultural research, as previous research did not anticipate the effect sizes observed here.

\section{Study limitations}

The specificness of the used samples is a limitation of the present study: the samples consisted of students from specific study domains at specific universities. Descriptive figures can vary with samples of other segments of populations. Yet, it is unlikely that the observed differences are specific to the samples and would not reflect similar differences across whole populations of the included country. Perhaps differences in representative samples are even larger as students have been more exposed to global media than older generations during their formative years, and hence more homogenous across countries. Future research with representative samples is needed to confirm differences between countries. Still, knowledge about wildlife value orientations of students is important as such, given that future leaders are likely to be students now (Straka et al. 2020).

\section{Conclusions}

Theory suggests wildlife value orientations reflect cultural ideologies and anticipates differences between countries (Manfredo et al. 2020). Our findings indicate that differences in students' orientations across the sampled countries are considerable when estimated on the level of individuals. Country explained $6 \%$ of the variance in domination and $21 \%$ of the variance in mutualism. When estimated on the level of countries, effect sizes were similar but not significant, due to the relatively small sample of seven countries. On the level of countries, then, findings do not allow a generalized conclusion transcending the current sample. Arriving at a global picture of variations in wildlife value orientations requires an interplay of qualitative studies to reveal potential additional beliefs, and quantitative studies to test the reliability and predictive potential of scales. The present study makes a contribution to the existing literature by providing evidence of variation across countries that merits further research, demonstrating that the existing scales are useful in research across countries in terms of reliability, and suggesting that the structure of hunting beliefs might vary across countries, as might associations between demographics and wildlife value orientations.

Our research underscores the importance of cross-national research in the context of global conservation challenges. Wildlife challenges, policy and management are often not 
confined to individual countries (Trouwborst 2015). For instance, in all member states, the same European Union laws apply to wolf conservation (Linnell et al. 2017; Trouwborst 2010). Yet, communities in the different EU countries respond very differently to wolves and wolf conservation. In some countries, illegal killing is more common than in other countries, for instance (Liberg et al. 2012; Salvatori and Linnell 2005). Therefore, it also varies across countries what the best way is to interact with the public. Cross-cultural studies comparing how people think about wildlife presents information that is useful for anticipating public responses to decisions and communication. Ultimately, understanding sources of diversity in thought about wildlife is crucial for effective biodiversity conservation.

Acknowledgements We thank all students who have participated in the survey. We thank the School of Life and Environmental Sciences at Deakin University and Dr. Amy Shaw for assistance with the online survey design.

Author contributions The study was conceived and designed by Maarten Jacobs. All authors contributed to material preparation and data collection. Maarten Jacobs carried out data analysis and wrote the first draft of the manuscript. All authors commented on and edited previous versions of the manuscript. All authors read and approved the final manuscript.

Funding Not applicable.

Data availability The dataset will be available at the website of the Wageningen University library.

\section{Declarations}

Conflict of interest No conflicts.

Animal research Not applicable.

Consent to participate All respondents were made aware of voluntary participation and have approved.

Consent to publish All respondents were made aware that data may be used for publications and have approved.

Plant reproducibility Not applicable.

Clinical trials registration Not applicable.

Open Access This article is licensed under a Creative Commons Attribution 4.0 International License, which permits use, sharing, adaptation, distribution and reproduction in any medium or format, as long as you give appropriate credit to the original author(s) and the source, provide a link to the Creative Commons licence, and indicate if changes were made. The images or other third party material in this article are included in the article's Creative Commons licence, unless indicated otherwise in a credit line to the material. If material is not included in the article's Creative Commons licence and your intended use is not permitted by statutory regulation or exceeds the permitted use, you will need to obtain permission directly from the copyright holder. To view a copy of this licence, visit http://creativecommons.org/licenses/by/4.0/. 


\section{References}

Anyango-Van Zwieten N, Lamers M, Van der Duim R (2019) Funding for nature conservation: a study of public finance networks at World Wide Fund for nature (WWF). Biodivers Conserv 28:3749-3766. https://doi.org/10.1007/s10531-019-01848-y

Bhandari S, Shrestha UB, Aryal A (2019) Increasing tiger mortality in Nepal: a bump in the road? Biodivers Conserv 28:4115-4118. https://doi.org/10.1007/s10531-019-01849-x

Bhatia S, Redpath SM, Suryawanshi K, Mishra C (2020) Beyond conflict: exploring the spectrum of humanwildlife interactions and their underlying mechanisms. Oryx 54:621-628. https://doi.org/10.1017/ S003060531800159X

Bouman T, Verschoor M, Albers CJ, Böhm G, Fisher SD, Poortinga W, Steg L (2020) When worry about climate change leads to climate action: How values, worry and personal responsibility relate to various climate actions. Glob Environ Change 62:102061. https://doi.org/10.1016/j.gloenvcha.2020.102061

Bruyere BL (2015) Giving Direction and Clarity to Conservation Leadership. Conserv Lett 8:378-382. https://doi.org/10.1111/conl.12174

Bryan ML, Jenkins SP (2015) Multilevel Modelling of Country Effects: A Cautionary Tale. Eur Sociol Rev 32:3-22. https://doi.org/10.1093/esr/jcv059

Camino M, de Sousa Mendes Parreira Cortez S, Altrichter M, Matteucci SD (2018) Relations with wildlife of Wichi and Criollo people of the Dry Chaco, a conservation perspective. Universidade Federal Rural de Pernambuco, Recife

Cerri J, Mori E, Vivarelli M, Zaccaroni M (2017) Are wildlife value orientations useful tools to explain tolerance and illegal killing of wildlife by farmers in response to crop damage? Eur J Wildl Res 63:70. https://doi.org/10.1007/s10344-017-1127-0

Decker DJ, Riley SJ, Siemer WF (2012) Human dimensions of wildlife management. JHU Press, Baltimore, Maryland

Dietsch AM, Teel TL, Manfredo MJ (2016) Social values and biodiversity conservation in a dynamic world. Conserv Biol 30:1212-1221. https://doi.org/10.1111/cobi.12742

Diez-Roux AV (2000) Multilevel analysis public health research. Annu Rev Public Health 21:171-192. https://doi.org/10.1146/annurev.publhealth.21.1.171

Dressel S, Sandström C, Ericsson G (2015) A meta-analysis of studies on attitudes toward bears and wolves across Europe 1976-2012. Conserv Biol 29:565-574. https://doi.org/10.1111/cobi.12420

Field A (2013) Discovering statistics using IBM SPSS statistics. Sage, London

Fulton DC, Manfredo MJ, Lipscomb J (1996) Wildlife value orientations: A conceptual and measurement approach. Hum Dimens Wildl 1:24-47. https://doi.org/10.1080/10871209609359060

Gächter S (2010) (Dis) advantages of student subjects: what is your research question? Behav Brain Sci 33:92-93

Gamborg C, Jensen FS (2016) Wildlife Value Orientations: A Quantitative Study of the General Public in Denmark. Hum Dimens Wildl. 21:34-46. https://doi.org/10.1080/10871209.2015.1098753

Harari YN (2014) Sapiens. A Brief History of Humankind. Vintage Books, London

Henrich J, Heine SJ, Norenzayan A (2010) The weirdest people in the world? Behav Brain Sci 33:61-83. https://doi.org/10.1017/S0140525X0999152X

Hermann N, Voß C, Menzel S (2013) Wildlife value orientations as predicting factors in support of reintroducing bison and of wolves migrating to Germany Journal for Nature Conservation 21:125-132. https:// doi.org/10.1016/j.jnc.2012.11.008

Hofstede G (2001) Culture's consequences: Comparing values, behaviors, institutions and organizations across nations. Sage, London

Inglehart R (1997) Modernization and postmodernization: Cultural, economic, and political change in 43 societies. Princeton University Press, Princeton

Inglehart R, Baker WE (2000) Modernization, cultural change, and the persistence of traditional values. Am Sociol Rev. 65:19-51. https://doi.org/10.2307/2657288

Jacobs MH, Vaske JJ, Dubois S, Fehres P (2014a) More than fear: Role of emotions in acceptability of lethal control of wolves European. J Wild Res 60:589-598. https://doi.org/10.1007/s10344-014-0823-2

Jacobs MH, Vaske JJ, Sijtsma MTJ (2014b) Predictive potential of wildlife value orientations for acceptability of management interventions. J Nature Conserv 22:377-383. doi:https://doi.org/10.1016/j. jnc.2014.03.005

Jacobs MH, Vaske JJ, Teel TL, Manfredo MJ (2019) Human dimensions of wildlife. In: Steg L, de Groot J (eds) Environmenal psychology: An introduction, Second edn. John Wiley \& Sons, Chicester, pp 85-94. https://doi.org/10.1002/9781119241072.ch9

Kluckhohn FR (1949) Dominant and substitute profiles of cultural orientations. Their significance for the analysis of social stratification. Soc Forces 28:376 
Kluckhohn FR, Strodtbeck FL (1961) Variations in value orientations. Peterson, Row

Koltko-Rivera ME (2004) The psychology of worldviews. Rev Gen Psychol 8:3-58

Kreft IG, De Leeuw J (1998) Introducing multilevel modeling. Sage, London

Lehman DR, Chiu C-y, Schaller M (2004) Psychology and culture. Annu Rev Psychol 55:689-714

Liberg O, Chapron G, Wabakken P, Pedersen HC, Hobbs NT, Sand H (2012) Shoot, shovel and shut up: cryptic poaching slows restoration of a large carnivore in Europe. Proc R Soc B: Biol Sci 279:910-915. https://doi.org/10.1098/rspb.2011.1275

Linnell J, Trouwborst A, Fleurke F (2017) When is it acceptable to kill a strictly protected carnivore? Exploring the legal constraints on wildlife management within Europe's Bern Convention. (In: Exploring the Legal Constraints on Wildlife Management within Europe's Bern Convention (September 13, 2017)). Nature Conserv 129-157

Macdonald E, Burnham D, Hinks A, Dickman A, Malhi Y, Macdonald D (2015) Conservation inequality and the charismatic cat: Felis felicis. Glob Ecol Conserv 3:851-866

Manfredo MJ (2008) Who cares about wildlife?: Social science concepts for exploring human-wildlife relationships and conservation issues. Springer, New York. https://doi.org/10.1007/978-0-387-77040-6

Manfredo MJ et al (2020) The changing sociocultural context of wildlife conservation. Conserv Biol 34:1549-1559. https://doi.org/10.1111/cobi.13493

Manfredo MJ, Teel TL, Henry KL (2009) Linking society and environment: A multilevel model of shifting wildlife value orientations in the western United States. Soc Sci Q 90:407-427. https://doi. org/10.1111/j.1540-6237.2009.00624.x

Nezlek JB (2008) An Introduction to Multilevel Modeling for Social and Personality Psychology. Soc Personal Psychol Compass 2:842-860. https://doi.org/10.1111/j.1751-9004.2007.00059.x

Ntuli H, Jagers SC, Linell A, Sjöstedt M, Muchapondwa E (2019) Factors influencing local communities' perceptions towards conservation of transboundary wildlife resources: the case of the Great Limpopo Trans-frontier Conservation Area. Biodivers Conserv 28:2977-3003. https://doi.org/10.1007/ s10531-019-01809-5

Pešić J (2006) Persistence of traditionalist value orientations in Serbia. Sociologija 48:289-307

Poortinga W, Whitmarsh L, Steg L, Böhm G, Fisher S (2019) Climate change perceptions and their individual-level determinants: A cross-European analysis. Glob Environ Change 55:25-35. https://doi. org/10.1016/j.gloenvcha.2019.01.007

Punzo G, Panarello D, Pagliuca MM, Castellano R, Aprile MC (2019) Assessing the role of perceived values and felt responsibility on pro-environmental behaviours: A comparison across four EU countries. Environ Sci Policy 101:311-322

Rad MS, Martingano AJ, Ginges J (2018) Toward a psychology of Homo sapiens: Making psychological science more representative of the human population. PNAS 115:11401-11405. https://doi.org/10.1073/ pnas. 1721165115

Salvatori V, Linnell J (2005) Report on the conservation status and threats for wolf (Canis lupus) in Europe. Coucil of Europe, Brussels

Schwartz S (2006) A theory of cultural value orientations: Explication and applications. Comp Sociol 5:137-182

Schwartz SH (1999) A theory of cultural values and some implications for work. Appl Psychol 48:23-47

Sijtsma MTJ, Vaske JJ, Jacobs MH (2012) Acceptability of Lethal Control of Wildlife that Damage Agriculture in the Netherlands. Soc Nat Resour 25:1308-1323. https://doi.org/10.1080/08941920.2012.684850

Stegmueller D (2013) How Many Countries for Multilevel Modeling? A Comparison of Frequentist and Bayesian Approaches American. J Political Sci 57:748-761. https://doi.org/10.1111/ajps.12001

Straka TM, Kendal D, van der Ree R (2016) When Ecological Information Meets High Wildlife Value Orientations: Influencing Preferences of Nearby Residents for Urban Wetlands. Hum Dimens Wildl 21:538554. https://doi.org/10.1080/10871209.2016.1198851

Straka TM, Miller KK, Jacobs MH (2020) Understanding the acceptability of wolf management actions: roles of cognition and emotion. Hum Dimens Wild 25:33-46

Tam K-P, Milfont TL (2020) Towards cross-cultural environmental psychology: A state-of-the-art review and recommendations. J Environ Psychol 71:101474

Teel TL, Manfredo MJ (2010) Understanding the diversity of public interests in wildlife conservation. Conserv Biol 24:128-139. https://doi.org/10.1111/j.1523-1739.2009.01374.x

Teel TL, Manfredo MJ, Stinchfield HM (2007) The Need and Theoretical Basis for Exploring Wildlife Value Orientations Cross-Culturally. Hum Dimens Wildl 12:297-305. https://doi. org/10.1080/10871200701555857

Trouwborst A (2010) Managing the Carnivore Comeback: International and EU Species Protection Law and the Return of Lynx, Wolf and Bear to Western Europe. J Environ Law 22:347-372. https://doi. org/10.1093/jel/eqq013 
Trouwborst A (2015) Global large carnivore conservation and international law. Biodivers Conserv 24:15671588. https://doi.org/10.1007/s10531-015-0894-8

Vaske JJ (2008) Survey research and analysis: Applications in parks, recreation and human dimensions. Venture Pub., State College

Vaske JJ, Jacobs MH, Sijtsma MTJ (2011a) Wildlife value orientations and demographics in The Netherlands European. J Wildl Res 57:1179-1187. https://doi.org/10.1007/s10344-011-0531-0

Vaske JJ, Jacobs MH, Sijtsma MTJ, Beaman J (2011b) Can Weighting Compensate for Sampling Issues in Internet Surveys? Hum Dimens Wildl 16:200-215. https://doi.org/10.1080/10871209.2011.571230

Vitule JRS et al (2019) Intra-country introductions unraveling global hotspots of alien fish species. Biodivers Conserv 28:3037-3043. https://doi.org/10.1007/s10531-019-01815-7

Whittaker D, Vaske JJ, Manfredo MJ (2006) Specificity and the Cognitive Hierarchy: Value Orientations and the Acceptability of Urban Wildlife Management Actions. Soc Nat Resour 19:515-530. https://doi. org/10.1080/08941920600663912

Zainal Abidin ZA (2019) Understanding human responses to wildlife in Malaysia. Wageningen University, Wageningen

Zainal Abidin ZA, Jacobs MH (2016) The Applicability of Wildlife Value Orientations Scales to a Muslim Student Sample in Malaysia. Hum Dimens Wildl 21:555-566. https://oi.org/10.1080/10871209.2016 .1199745

Zinn HC, Manfredo MJ, Vaske JJ, Wittmann K (1998) Using normative beliefs to determine the acceptability of wildlife management actions. Soc Natural Resour 11:649-662. https://oi. org/10.1080/08941929809381109

Publisher's note Springer Nature remains neutral with regard to jurisdictional claims in published maps and institutional affiliations.

\section{Authors and Affiliations}

\section{Maarten H Jacobs ${ }^{1}$. Sara Dubois ${ }^{2}$. Tetsuro Hosaka ${ }^{3}$. Vukan Ladanović ${ }^{4}$. Huda Farhana Mohamad Muslim ${ }^{5}$ Kelly K. Miller ${ }^{6}$ Shinya Numata7 .

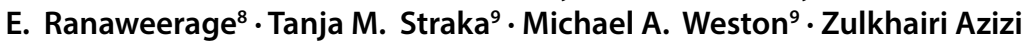 Zainal Abidin ${ }^{10}$}

Maarten H Jacobs Ph.D

maarten.jacobs@wur.nl

1 Cultural Geography Chair Group, Wageningen University, Droevendaalsesteeg 3, 6708 PB Wageningen, The Netherlands

2 Applied Biology Program, University of British Columbia, Vancouver Campus, 2357 Main Mall, V6T 1 Z4 Vancouver, Canada

3 Graduate School of Advanced Science and Engineering, Hiroshima University, 1-5-1, Kagamiyama, Higashihiroshima, 739-8529 Hiroshima, Japan

4 Faculty of Forestry, University of Belgrade, Kneza Višeslava 1, 11030 Belgrade, Serbia

5 Social Forestry Program, Forest Research Institute Malaysia, 52109 Kepong, Selangor Darul Ehsan, Malaysia

6 School of Life and Environmental Science, Centre for Integrative Ecology, Deakin University, Melbourne Burwood Campus, Locked Bag 20000, VIC 3220 Geelong, Australia

7 Department of Tourism Science, Tokyo Metropolitan University, Minawi-Osawa Campus 1-1, Minawi-Osawa, 192-0397 Tokyo, Japan

8 Institute of Ecology, Technische Universität Berlin, Rothenburgstrasse 12, D-12165 Berlin, Germany 
$9 \quad$ School of Life and Environmental Science, Deakin University, Melbourne Burwood Campus. 221 Burwood Highway, Geelong, Australia

10 Department of Recreation and Ecotourism, Universiti Putra Malaysia, 43400 UPM Serdang, Malaysia 